\title{
A glucose-controlled insulin infusion system for diabetic women during labour
}

\author{
M NATTRASS, K G M M ALBERTI, K J DENNIS, P N GILLIBRAND, \\ A T LETCHWORTH, A L J BUCKLE
}

\section{Patients and methods}

Table I shows details of the six patients.

Case 1-This 21-year-old primigravida had been diabetic for 10 years. She was studied after the onset of spontaneous labour at 37 weeks' gestation. Her diabetes was well controlled during pregnancy with twice-daily injections of Actrapid MC (neutral insulin injection) and Retard (RI) (isophane insulin injection), and her usual morning dose had been given two hours before the onset of labour.

Case 2-This 24-year-old woman was in her fourth pregnancy. Diabetes was diagnosed during her first pregnancy three years previously, which had resulted in a live infant with multiple congenital abnormalities, who died eight hours after birth. Two further pregnancies had resulted in mid-trimester abortions, and during the fourth pregnancy a Shirodkar suture was inserted at 13 weeks. Her diabetes was well controlled throughout pregnancy on twice-daily injections of Actrapid MC and Retard (RI) insulins. Labour was induced at 38 weeks' gestation when the amniotic fluid lecithin: sphingomyelin $(\mathrm{L}: \mathrm{S})$ ratio showed adequate pulmonary surfactant.

Case 3-This 24-year-old woman was studied during her second pregnancy. Three years previously her first pregnancy had been terminated at 32 weeks' gestation by caesarean section because of pre-eclampsia. The infant developed hyaline membrane disease and died eight days after birth. Diabetes had been present for 20 years and was well controlled during pregnancy by twice daily injections of Actrapid MC and Retard (RI) insulins. She developed proteinuria early in pregnancy, which became progressively more apparent (2-6 g/day) from 32 weeks' gestation. This was accompanied by a rise in diastolic pressure $(105-110 \mathrm{~mm} \mathrm{Hg}$ ). After the onset of uterine contractions caesarean section was performed at 36 weeks' gestation.

Case 4-This 23-year-old primigravida had a 13-year history of diabetes. In the two years before pregnancy she had been treated for extensive formation of new vessels in the retina with argon and xenon lasers (Mr A M Hamilton, Moorfields Eye Hospital), which had resulted in regression of the new vessels, and retinopathy did not advance during pregnancy. Her diabetes was well controlled in pregnancy with twice-daily injections of Actrapid MC and Retard (RI) insulins, and labour was induced at $37 \frac{1}{2}$ weeks when the $\mathrm{L}: \mathrm{S}$ ratio indicated fetal maturity. Oxytocin (Syntocinon) in $5 \%$ or $10 \%$ dextrose was infused, but over the following 10 hours labour failed to progress and caesarean section was performed.

Case 5-This 38-year-old woman, who had been diabetic for 17 years, was in her fifth pregnancy. In the preceding six years she had had two stillbirths at 37 weeks' gestation, one spontaneous abortion, and one live birth. Her diabetes was well controlled throughout pregnancy with twice-daily injections of Actrapid MC and Monotard MC (insulin zinc suspension) insulins, and labour was induced at 38 weeks with oxytocin in $5 \%$ dextrose.

Case 6-This 21-year-old primigravida had had diabetes for seven years. During most of her pregnancy diabetes was well controlled with twice-daily injections of Actrapid $M C$ and Monotard MC insulins except for a mild episode of diabetic ketoacidosis at 30 weeks'

A T LETCHWORTH, MD, MRCOG, senior lecturer in human reproduction and obstetrics

TABLE I-Type of delivery and gestational age and outcome of pregnancy in six diabetic women whose blood glucose concentration was controlled during labour by glucose-controlled insulin infusion system

\begin{tabular}{|c|c|c|c|c|c|c|}
\hline \multirow{2}{*}{ Case No } & \multirow{2}{*}{ Type of delivery } & \multirow{2}{*}{$\begin{array}{l}\text { Gestational age } \\
\text { (weeks) }\end{array}$} & \multirow{2}{*}{$\begin{array}{c}\text { Birth weight } \\
\text { of infant } \\
(\mathrm{g})\end{array}$} & \multicolumn{2}{|c|}{ Apgar scores } & \multirow{2}{*}{ Progress of infant } \\
\hline & & & & $1 \mathrm{~min}$ & $5 \mathrm{~min}$ & \\
\hline $\begin{array}{l}1 \\
2 \\
3 \\
4 \\
5 \\
6\end{array}$ & $\begin{array}{l}\text { Spontaneous labour } \\
\text { Induction of labour } \\
\text { Caesarean section } \\
\text { Failed induction of labour } \\
\text { Induction of labour } \\
\text { Caesarean section }\end{array}$ & $\begin{array}{l}37 \\
38 \\
36 \\
37 \frac{1}{2} \\
38 \\
37\end{array}$ & $\begin{array}{l}3180 \\
2530 \\
2880 \\
2540 \\
3845 \\
3000\end{array}$ & $\begin{array}{l}8 \\
7 \\
7 \\
6 \\
9 \\
7\end{array}$ & $\begin{array}{r}10 \\
9 \\
8 \\
10 \\
10 \\
9\end{array}$ & $\begin{array}{l}\text { Satisfactory } \\
\text { Satisfactory } \\
\text { Died at } 12 \text { days } \\
\text { Satisfactory } \\
\text { Satisfactory } \\
\text { Satisfactory }\end{array}$ \\
\hline
\end{tabular}


gestation. At 34 weeks' gestation she developed proteinuria and raised diastolic blood pressure, which ranged from 2 to $5 \mathrm{~g}$ /day and from 110 to $120 \mathrm{~mm} \mathrm{Hg}$ respectively over the next three weeks. At 37 weeks the $\mathrm{L}: \mathrm{S}$ ratio indicated maturity and an elective caesarean section was performed.

\section{GLUCOSE-CONTROLLED INSULIN INFUSION SYSTEM}

The gluoose-controlled insulin infusion system (Biostator System, Life Science Instruments, Miles Laboratories, Elkart, Indiana) has been described in detail elsewhere. ${ }^{4}$ Venous blood was withdrawn continuously through the inner lumen of a double-lumen cannula sited in a forearm vein. Blood was diluted and prevented from clotting by heparin and edetic acid in saline $0.154 \mathrm{~mol} / 1$ pumped down the outer lumen of the cannula. Continuous measurement of blood glucose concentration was performed with a glucose electrode-glucose oxidase method. The results were obtained 90 seconds after sampling and passed to a computer controlling an infusion system with options to infuse saline, saline and insulin, or saline and dextrose through a second cannula in the antecubital fossa of the same arm. The response of the infusion system to the patients' blood glucose concentration or rate of change of blood glucose concentration was determined by two sets of preprogrammed algorithms. The response was modified by keyboard instructions about the desired blood glucose concentration in the patient.

\section{PROCEDURE}

In the three women (cases $2,4,5$ ) in whom labour was induced indwelling intravenous cannulae were inserted immediately after a light breakfast. As soon as satisfactory venous withdrawal was ensured delivery of insulin or dextrose under computer control was begun. The usual morning subcutaneous injection of insulin was withheld. In patients undergoing elective caesarean section (cases 3 and 6) delivery of insulin or dextrose by the glucose-controlled insulin infusion system was started over an hour before operation. The patient (case 1) who went into spontaneous labour had her usual morning subcutaneous insulin and was connected to the glucosecontrolled insulin infusion system four hours after this and two hours after the onset of uterine contractions.

Control of blood glucose concentration by the glucose-controlled insulin infusion system was continued for the duration of labour or operation and for at least one more hour, except in one patient (case 4 ), in whom the infusion system was used only for the attempted induction of labour and not the caesarean section.

\section{Results}

CONTROL OF BLOOD GLUCOSE DURING LABOUR

Mean blood glucose concentration for the four women during labour is shown in figure 1. Delivery occurred $7 \frac{1}{2}$ to 15 hours after starting treatment with the glucose-controlled insulin infusion system. Control of blood glucose concentration was good after the first $1 \frac{1}{2}$ hours when the mean blood glucose concentration fell from 8.7 $\mathrm{mmol} / 1 \quad(156.8 \mathrm{mg} / 100 \mathrm{ml})$ to $5.5 \mathrm{mmol} / 1(99.1 \mathrm{mg} / 100 \mathrm{ml})$. From $4 \frac{1}{2}$ to $9 \frac{1}{2}$ hours, when three of the deliveries occurred, mean blood glucose concentration was in the range $4 \cdot 6-5 \cdot 2 \mathrm{mmol} / 1(82 \cdot 9-93.7 \mathrm{mg}$ /
$100 \mathrm{ml}$ ). Individual blood glucose concentrations immediately before birth are shown in table II. The system was programmed to maintain blood glucose concentration in the range $5 \cdot 0-6 \cdot 5 \mathrm{mmol} / 1(90 \cdot 1-117 \cdot 1$ $\mathrm{mg} / 100 \mathrm{ml})$. The total amount of insulin infused is presented firstly as the amount necessary to achieve a blood glucose concentration of $6.5 \mathrm{mmol} / \mathrm{l}$, and secondly as the amount needed to maintain blood glucose concentration below $6.5 \mathrm{mmol} / \mathrm{l}$ (table II). There were considerable differences between patients in the amounts of insulin

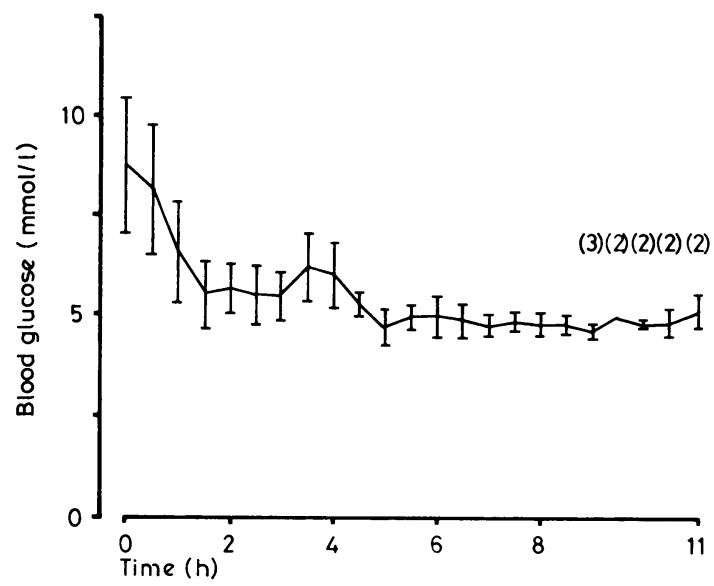

FIG 1-Mean ( $t$ SE of mean) blood glucose concentration during labour in insulin-dependent diabetics. Time is calculated from start of treatment with glucose-controlled insulin infusion system. Number of patients was four, except where stated otherwise (numbers in parentheses)

Conversion: SI to traditional units-Blood glucose: $1 \mathrm{mmol} / 1 \approx 18 \mathrm{mg} / 100 \mathrm{ml}$.

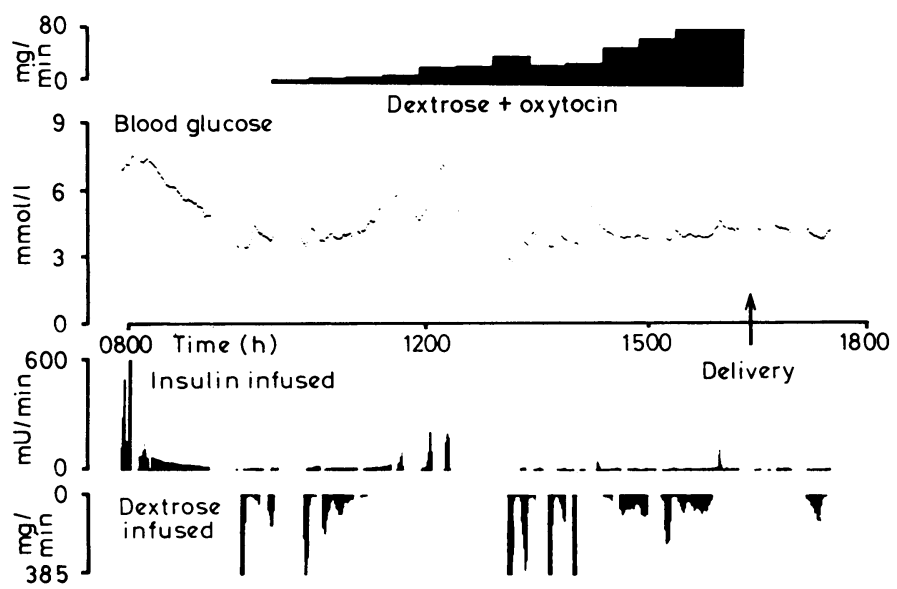

FIG 2-Case 2. Blood glucose concentration, rates of infusion of insulin and dextrose by glucose-controlled insulin infusion system, and rates of infusion of dextrose and oxytocin during induction of labour in an insulin-dependent diabetic woman.

TABLE II-Control of blood glucose concentration by glucose-controlled insulin infusion system in six insulin-dependent diabetic women during delivery

\begin{tabular}{|c|c|c|c|c|c|c|c|c|c|}
\hline \multirow{2}{*}{$\begin{array}{l}\text { Case } \\
\text { No }\end{array}$} & \multicolumn{2}{|c|}{$\begin{array}{l}\text { Blood glucose } \\
(\mathrm{mmol} / \mathrm{l})\end{array}$} & \multirow{2}{*}{$\begin{array}{c}\text { Total } \\
\text { insulin } \\
\text { infused } \\
(\mathbf{U})\end{array}$} & \multicolumn{2}{|c|}{$\begin{array}{l}\text { Dextrose infusion } \\
(\mathrm{g})\end{array}$} & \multicolumn{2}{|c|}{$\begin{array}{l}\text { Insulin infusion rates } \\
(\mathrm{U} / \mathrm{h})\end{array}$} & \multicolumn{2}{|c|}{ Average infusion rates } \\
\hline & $\begin{array}{c}\text { Initial } \\
\text { concentration }\end{array}$ & $\begin{array}{c}\text { At } \\
\text { delivery }\end{array}$ & & By & $\begin{array}{c}\text { Intra- } \\
\text { venously }\end{array}$ & $\begin{array}{l}\text { 1o achieve } \\
\text { normo- } \\
\text { glycaemia* }\end{array}$ & $\begin{array}{l}\text { 10 maintain } \\
\text { normo- } \\
\text { glycaemia* }\end{array}$ & $\begin{array}{c}\text { Insulin } \\
(\mathrm{U} / \mathrm{h})\end{array}$ & $\begin{array}{c}\text { Dextrose } \\
(\mathrm{g} / \mathrm{h})\end{array}$ \\
\hline $\begin{array}{l}1 \\
2 \\
3 \\
4 \\
5 \\
6\end{array}$ & $\begin{array}{r}5.5 \\
7.0 \\
8.5 \\
9.0 \\
13.5 \\
10.5\end{array}$ & $\begin{array}{l}6 \cdot 0 \\
4 \cdot 4 \\
8 \cdot 5 \\
4.5 \\
5 \cdot 4 \\
5 \cdot 0\end{array}$ & $\begin{array}{r}2 \cdot 6 \\
10 \cdot 9 \\
8 \cdot 4 \\
137 \cdot 7 \\
51 \cdot 1 \\
27 \cdot 8\end{array}$ & $\begin{array}{c}46 \cdot 0 \\
19 \cdot 8 \\
0 \\
0 \\
0 \\
0\end{array}$ & $\begin{array}{c}0 \\
8 \cdot 5 \\
0 \\
90 \cdot 5 \\
56 \cdot 0 \\
0\end{array}$ & $\begin{array}{r}0 \\
9 \cdot 4 \\
2 \cdot 3 \\
17 \cdot 0 \\
17 \cdot 3 \\
10 \cdot 1\end{array}$ & $\begin{array}{l}0.2 \\
0 \cdot 7 \\
1 \cdot 6 \\
6 \cdot 7 \\
3.9 \\
1.9\end{array}$ & $\begin{array}{l}0.2 \\
1 \cdot 2 \\
2 \cdot 1 \\
9 \cdot 8 \\
5 \cdot 9 \\
4 \cdot 6\end{array}$ & $\begin{array}{l}2 \cdot 9 \\
3 \cdot 0 \\
0 \\
6 \cdot 5 \\
6 \cdot 4 \\
0\end{array}$ \\
\hline
\end{tabular}

*Blood glucose concentration $\leqslant 6 \cdot 5 \mathrm{mmol} / 1(117 \cdot 1 \mathrm{mg} / 100 \mathrm{ml})$.

Conversion: SI to traditional units-Blood glucose: $1 \mathrm{mmol} / 1 \approx 18 \mathrm{mg} / 100 \mathrm{ml}$. 
infused, ranging from $0.2 \mathrm{U} / \mathrm{h}$ in the patient given her normal morning insulin to $9.8 \mathrm{U} / \mathrm{h}$ in the patient given oxytocin in $10 \%$ dextrose.

Figure 2 shows results during induction of labour in one patient (case 2). Initial blood glucose concentration after a light breakfast was $7.0 \mathrm{mmol} / 1(126.1 \mathrm{mg} / 100 \mathrm{ml})$; over the first hour blood glucose concentration was lowered to $5.5 \mathrm{mmol} / \mathrm{l}(99.1 \mathrm{mg} / 100 \mathrm{ml})$ by infusions of 5.4 units of insulin. Thereafter it remained in the range $3 \cdot 5-5 \cdot 0 \mathrm{mmol} / 1(63 \cdot 1-90 \cdot 1 \mathrm{mg} / 100 \mathrm{ml})$ until delivery. In addition to the infusion of $8.5 \mathrm{~g}$ dextrose as $5 \%$ dextrose solution with oxytocin, $19.8 \mathrm{~g}$ dextrose was infused under control of the glucose-controlled insulin infusion system.

\section{CONTROL OF BLOOD GLUCOSE DURING CAESAREAN SECTION}

Figure 3 shows the results obtained in a patient undergoing caesarean section. Preoperatively blood glucose concentration was lowered from $10.5 \mathrm{mmol} / 1(189.2 \mathrm{mg} / 100 \mathrm{ml})$ to $5.0 \mathrm{mmol} / 1(90.1 \mathrm{mg} /$ $100 \mathrm{ml}$ ), and during operation it was maintained at $5.0 \mathrm{mmol} / 1$. The total amount of insulin infused before and during operation was $21 \cdot 1 \mathrm{U}$ over three hours.

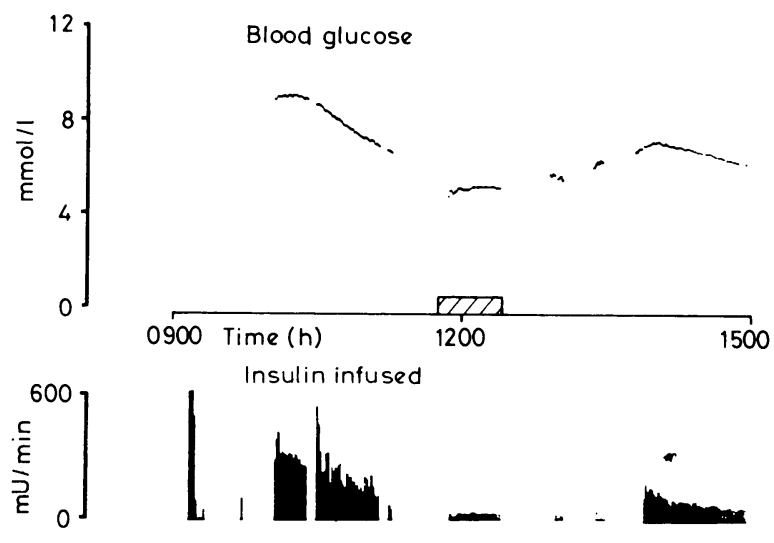

FIG 3-Case 6. Blood glucose concentration and rate of insulin infusion by glucose-controlled insulin infusion system during delivery by caesarean section in an insulin-dependent diabetic. Hatched area shows time of caesarean section.

\section{Discussion}

In normal people insulin secretion by the pancreas is regulated from minute to minute by changes in blood glucose concentration. Glucose-controlled insulin infusion systems restore the relation between blood glucose concentration and insulin delivery to normal and are effective in maintaining normoglycaemia in brittle diabetes, ${ }^{5}$ diurnal studies, ${ }^{6}$ and exercise ${ }^{7}$ in insulindependent diabetes. Maintaining normoglycaemia in diabetic women during labour or surgery is a logical aim, and we have shown that this can be successfully achieved by a glucosecontrolled insulin infusion system.

With the simpler glucose-insulin infusion system ${ }^{12}$ initially high maternal blood glucose concentrations took longer to correct and there was an increased risk of maternal hypoglycaemia. In addition, the range of blood glucose concentration immediately before delivery was greater than in our study. A glucose-controlled insulin infusion system allows the blood glucose concentration to return rapidly to normal and normoglycaemia is maintained without the dangers of maternal hypoglycaemia.

Enthusiasm for the glucose-controlled insulin infusion system must be tempered, however, by recognising its present limitations. The accurate, rapid measurement of blood glucose concentration and the degree of sophistication of the computer algorithms in determining infusion responses depend entirely on maintaining a constant, continuous blood flow through the double-lumen cannula. Deviation from the desired blood glucose concentration in our patients was largely due to interruptions in sampling, which were sometimes occasioned by venospasm and small blood clots in the cannula but more often by transferring the patient to the labour ward, inserting an epidural catheter, removing a Shirodkar suture, and artificial rupture of membranes. Blood flow was not a problem, however, during the strenuous exertion of the second part of labour.

Considerable familiarity with the responses of the glucosecontrolled insulin infusion system in different circumstances is essential if problems are to be avoided. For example, a change in constants is necessary at delivery. The basal rate of insulin infusion, which is defined as the rate needed to maintain the desired blood glucose concentration, must be immediately reduced at the end of the third part of labour if a precipitous fall in blood glucose concentration is to be avoided. All the women produced live infants. Nevertheless, the infant of one (case 3) had generalised oedema at birth. The infant developed intractable hypoglycaemia and renal failure and died 12 days after birth with a neonatal hepatitis syndrome. The remaining infants did not have neonatal hypoglycaemia and their progress was uneventful.

Using a glucose-controlled insulin infusion system has several advantages. Feedback control of blood glucose concentration allows maternal blood glucose concentration to be controlled before and during delivery. This may be important in avoiding neonatal hypoglycaemia. ${ }^{8}$ In addition, the metabolic state of the patient in lengthy labour may be a factor in deciding to terminate it by caesarean section ${ }^{9}$; but if the obstetrician knows that the blood glucose concentration will remain stable he will be unhampered by metabolic considerations when taking decisions on managing parturition in insulin-dependent diabetic women.

We thank the British Diabetic Association for financial support.

\section{References}

1 West, T E T, and Lowy, C, British Medical fournal, 1977, 1, 1252.

Watkins, P J, Fournal of the Royal Society of Medicine, 1978, 71, 202

${ }^{3}$ White, P, in Foslin's Diabetes Mellitus, ed A Marble et al, p 592. Philadelphia, Lea and Febiger, 1971.

${ }^{4}$ Clemens, A H, et al, fournées Annuelles de Diabétologie de L'Hôtel-Dieu, p 269. Paris, Flammarion Médecine-Sciences, 1976.

${ }^{5}$ Albisser, A M, and Leibel, B S, Clinics in Endocrinology and Metabolism, 1977, 6, 457 .

${ }^{6}$ Buckle, A L J, et al, Diabetologia, 1977, 13, 385.

${ }^{7}$ Murray, F T, et al, fournal of Clinical Endocrinology and Metabolism, 1977, 44, 708.

${ }^{8}$ Persson, B, in Carbohydrate Metabolism in Pregnancy and the Newborn, ed $\mathrm{H}$ W Sutherland and J M Stowers, p 106. Edinburgh, Churchill Livingstone, 1975.

${ }^{9}$ Brudenell, $M$, in Carbohydrate Metabolism in Pregnancy and the Newborn, ed $\mathrm{H}$ W Sutherland and J M Stowers, p 221. Edinburgh, Churchill Livingstone, 1975.

(Accepted 30 fune 1978)

ONE HUNDRED YEARS AGO In Mr Baber's recently published official report on the route of Mr Grosvenor's mission through the great opium-growing districts of China, between Ssu-chan and Yuman, it is said the whole district is given over, for hundreds of miles, to the cultivation of opium and ducks, called locally "opiumducks," which frequently supplied Mr Baber and his party with a meal, and do, he says, really appear to stupefy themselves by feeding on the narcotic vegetable. They allowed the travellers to walk openly up to within 20 yards of them, and even then they rose very languidly. The natives assert that the flesh of these birds is so impregnated with laudanum, as to exercise a soporific influence on the consumer. But a little more careful verification is necessary before a story of this kind is accepted in all its details. (British Medical fournal, 1878.) 